\title{
¿VULNERACIÓN DE “DERECHOS FUNDAMENTALES \\ FAMILIARES"?: BREVES APUNTES A PROPÓSITO DEL CASO \\ COMUNIDAD CAMPESINA SANTA BÁRBARA VS. PERÚ.
}

\section{VIOLATION OF "FUNDAMENTAL FAMILY RIGHTS": BRIEF NOTES ON THE SANTA BÁRBARA PEASANT COMMUNITY V. PERU CASE.}

Bruno Novoa Campos ${ }^{1}$

\section{Resumen}

El autor propone, a propósito de la sentencia emitida por la Corte Interamericana de Derechos Humanos en referencia al caso comunidad campesina Santa Bárbara vs. Perú, la posibilidad de vulnerar derechos fundamentales familiares; así como, un método de estudio pertinente para abordarlos.

Palabras Clave: Corte Interamericana de Derechos Humanos, Tribunal Constitucional, derechos fundamentales familiares.

\section{Abstract}

In connection with the decision handed down by the Inter-American Court of Human Rights in Santa Bárbara peasant community v. Peru, the author suggests that fundamental family rights may well be violated and proposes a relevant method of study to address them.

Keywords: Inter-American Court of Human Rights, Constitutional Court of Peru, fundamental family rights. 


\section{CONTENIDO}

I. Caso comunidad campesina de Santa Bárbara vs Perú; II. ¿Cómo aborda actualmente el Tribunal Constitucional peruano los derechos fundamentales?; III. ¿Cómo aborda actualmente la Corte Interamericana de Derechos Humanos los derechos fundamentales?; IV. ¿Existe la posibilidad de vulnerar derechos fundamentales familiares?; V. Apuntes finales.

\section{CASO COMUNIDAD CAMPESINA DE SANTA BÁRBARA VS PERÚ}

El 2 de julio de 1991, en ejecución del "Plan Operativo Apolonia", operativo militar diseñado como parte de la política estatal de combatir la subversión en la Provincia y Departamento de Huancavelica, salieron de Bases Militares la patrulla "Escorpio" y la patrulla "Ángel" con el fin específico de incursionar en la localidad de Rodeopampa, comunidad de Santa Bárbara y "capturar y / o destruir" elementos terroristas que operaban en dicha zona. El 4 de julio de 1991 la patrulla del Ejército "Escorpio", acompañada de algunos elementos civiles, llegó al caserío de Rodeopampa en la comunidad campesina de Santa Bárbara, en donde los efectivos militares ingresaron a las viviendas de las presuntas víctimas, sacaron a quienes estaban allí y prendieron fuego a dichas viviendas para horas más tarde apoderarse de una gran cantidad de ganado, animales menores y pertenencias de los detenidos. Los efectivos militares detuvieron a 14 pobladores, entre los que se encontraban tres niñas y cuatro niños entre las edades de 8 meses y 6 años de edad, un hombre adulto mayor, cinco mujeres adultas, una de ellas en el sexto mes de embarazo y un hombre adulto. A dichos pobladores se les infligieron diversos maltratos, conduciéndolos hacia una mina abandonada llamada "Misteriosa" o "Vallarón". Ese mismo día Elihoref Huamaní Vergara fue interceptado por efectivos militares en el camino hacia Rodeopampa, quienes lo sumaron al grupo de los 14 pobladores que trasladaban. Durante el trayecto, los detenidos fueron golpeados y obligados a caminar varias horas amarrados y sin alimentos ni agua. Cuando llegaron a la mina abandonada llamada "Misteriosa" o "Vallarón", los efectivos militares introdujeron a los 15 detenidos al interior del socavón, acribillándolos con Fusiles Ametralladoras Ligeras (FAL). Posteriormente, se hizo detonar en la mina cargas de dinamita, provocando el fraccionamiento de los cuerpos².

Tomado del resumen oficial emitido por la Corte Interamericana de Derechos Humanos en referencia al caso denominado: "caso comunidad campesina de Santa Bárbara vs Perú". 
El extracto que acaba de leer se refiere al caso denominado: "comunidad campesina de Santa Bárbara vs Perú" que tuvo que esperar 24 años para llegar a la Corte Interamericana de Derechos Humanos y, por presión internacional, 26 años para que el Estado peruano culmine las investigaciones necesarias y entregue los restos a sus familiares.

\section{II. ¿CÓMO ABORDA ACTUALMENTE EL TRIBUNAL CONSTITU- CIONAL PERUANO LOS DERECHOS FUNDAMENTALES?}

El Tribunal Constitucional, recurriendo a la doctrina, considera que el concepto de los derechos fundamentales comprende lo siguiente:

(...) tanto los presupuestos éticos como los componentes jurídicos, significando la relevancia moral de una idea que compromete la dignidad humana y sus objetivos de autonomía moral, y también la relevancia jurídica que convierte a los derechos en norma básica material del Ordenamiento, y es instrumento necesario para que el individuo desarrolle en la sociedad todas sus potencialidades.[Cursivas añadidas]. Los derechos fundamentales expresan tanto una moralidad básica como una juridicidad básica (Peces-Barba, Gregorio. Curso de Derechos Fundamentales. Teoría General. Madrid: Universidad Carlos III de Madrid. Boletín Oficial del Estado, 1999, pág. 37)³

Del mismo modo, el Tribunal Constitucional recuerda que "(...) los derechos fundamentales constituyen conquistas del individuo frente al Estado (...)"4

En tal sentido, el Tribunal Constitucional ha establecido, por ejemplo, “(...) que el proceso de amparo está destinado exclusiva y excluyentemente a la defensa de los derechos fundamentales directamente relacionados a la persona humana [Cursivas añadidas] (... $)^{\prime \prime 5}$

Como se puede apreciar de la jurisprudencia emitida por el Tribunal Constitucional, el "individuo" constituye eje central de los derechos fundamentales. Y en efecto, el Tribunal Constitucional ha sido consecuente en su desarrollo jurisprudencial en mérito a lo señalado en el artículo $1^{\circ}$ de la Constitución que establece que "la defensa de la persona humana [Cursivas añadidas] y el respeto de su dignidad son el fin supremo de la sociedad y del Estado".

\footnotetext{
Exp. N¹417-2005-AA/TC.

Exp. 00898-2008-PA/TC.

Exp. N ${ }^{\circ}$ 00065-2008-PA/TC.
} 


\section{III. ¿CÓMOABORDAACTUALMENTELACORTEINTERAMERICANA DE DERECHOS HUMANOS LOS DERECHOS FUNDAMENTALES?}

La Corte, en referencia al debido proceso, ha establecido que "(...) el Estado tiene la responsabilidad de consagrar normativamente y de asegurar la debida aplicación de las garantías del debido proceso legal ante las autoridades competentes, que amparen a todas las personas [Cursivas añadidas] bajo su jurisdicción contra actos que violen sus derechos fundamentales o que conlleven a la determinación de los derechos y obligaciones de estas $(\ldots)^{\prime \prime 6}$

En esa misma línea, en referencia al derecho a la defensa, la Corte ha establecido que "[i]mpedir que la persona ejerza su derecho de defensa, desde que se inicia un proceso que la involucra y la autoridad dispone o ejecuta actos que implican afectación de derechos, es potenciar los poderes investigativos del Estado en desmedro de derechos fundamentales de la persona". ${ }^{7}$ [Cursivas añadidas]

En el ámbito de derecho público, la Corte ha señalado que los “(...) funcionarios públicos tienen una posición de garante de los derechos fundamentales de las personas [Cursivas añadidas] $\mathrm{y}$, por tanto, sus declaraciones no pueden desconocer éstos ni constituir formas de injerencia directa o indirecta o presión lesiva en los derechos de quienes pretenden contribuir a la deliberación pública mediante la expresión y difusión de su pensamiento $(. . .)^{\prime \prime 8}$

En el ámbito penal, la Corte ha considerado que "nadie puede ser sometido a detención o encarcelamiento por causas y métodos que -aún calificados de legales- puedan reputarse como incompatibles con el respeto a los derechos fundamentales del individuo por ser, entre otras cosas, irrazonables, imprevisibles, ofaltos de proporcionalidad". ${ }^{\prime}$

Como se puede apreciar de la jurisprudencia emitida por la Corte Interamericana de Derechos Humanos, el "individuo" o la "persona" constituye, al unísono que lo señalado por el Tribunal Constitucional, eje central de los derechos fundamentales. Y en efecto, la Corte ha sido consecuente en su desarrollo jurisprudencial en mérito a lo señalado en el artículo $1^{\circ}$ de la Convención Americana de Derechos Humanos que

Corte IDH. Caso Baena Ricardo y otros vs. Panamá. Competencia. Sentencia de 28 de noviembre de 2003. Serie C No. 104, párr. 79, y Caso Mohamed vs. Argentina. op. cit., párr. 83

Corte IDH. Caso Barreto Leiva vs. Venezuela, op. cit., párr. 29, y Caso López Mendoza vs. Venezuela, op. cit., párr. 117 https:/ / www.nytimes.com/es/tag/indice-global-de-esclavitud/?mcubz=1. Página visita el 28 de agosto de 2017.

Caso Gangaram Panday Vs. Suriname. Fondo, Reparaciones y Costas. Sentencia de 21 de enero de 1994. Serie C No.

16, párr. 47 y Caso Torres Millacura y otros Vs. Argentina, supra nota 17, párrs. 77 y 78. 
establece que "los Estados Partes (...) se comprometen a (...) garantizar su libre y pleno ejercicio a toda persona que esté sujeta a su jurisdicción [Cursivas añadidas] (...)".

En talcontexto, actualmentela protección delos derechos fundamentales en el Tribunal Constitucional y en la Corte Interamericana se centran en la defensa de la persona humana, tal como se aprecia a continuación:

(...) La legitimidad del Estado democrático y constitucional en América Latina no radica sólo en el origen de unas elecciones limpias y transparentes que sienten las bases de un Estado de Derecho, sino también en la radical protección y el mayor fomento de los derechos fundamentales, en tanto la defensa de la persona humana y el respeto de su dignidad [Cursivas añadidas], deben ser los fundamentos del orden social y jurídico de los estados con democracias débiles, en tanto aseguran la paz y garantizan el desarrollo (...) (Landa, 1998 p. 96, 97)

\section{IV. ¿EXISTE LA POSIBILIDAD DE VULNERAR DERECHOS FUNDA- MENTALES FAMILIARES?}

Ahora bien, el caso Santa Bárbara vs Perú resalta la abusiva detención, entre otros, de tres niñas y cuatro niños, entre los 8 meses y 6 años de edad, y el de una mujer adulta en el sexto mes de embarazo.

En tal escenario, la preocupación que se busca abordar, al menos inicialmente, se centra en presentar ante la academia, la posibilidad de determinar un nuevo enfoque, análisis, estudio, defensa u otro, que sirva de guía de los juristas, abogados y defensores de derechos humanos, ante casos similares al de Santa Bárbara.

Es decir, si bien el TC y la Corte Interamericana consideran a la persona o individuo como el eje central de su jurisprudencia, en concordancia con lo dispuesto por la Constitución y la Convención respectivamente ${ }^{10}$, preocupa que ante casos similares al de Santa Bárbara tan solo se realice un enfoque de los derechos fundamentales desde la persona y no desde la familia.

Expliquémonos, es claro que los derechos fundamentales tienen su origen y fin en la persona humana y sus derechos consagrados, a nivel constitucional y convencional, así como, la jurisprudencia emitida por el TC y la Corte Interamericana, se desarrollan considerando al hombre como eje;

10 Cabe precisar, que el TC ha considerado, asimismo, que las personas jurídicas también son titulares de derechos fundamentales (STC Exp. № 00605-2008-PA/TC). 
sin embargo, buscamos expandir su alcance para casos donde se vulneren derechos fundamentales familiares.

En efecto, lo que deseamos determinar no es un "derecho fundamental a la familia", que en todo caso se encuentra conformado por diferentes derechos fundamentales de los integrantes de la familia o por el derecho fundamental de alguno de sus miembros para conformar o establecer una familia; sino, "derechos fundamentales familiares".

Los derechos fundamentales familiares no buscan sumar derechos fundamentales particulares, que por cierto son muy importantes, sino que, sobre todo -y en forma adicional a los derechos fundamentales de cada uno de sus miembros- busca que se establezca un "enfoque y/o parámetro de estudio y/o defensa de mayor valor cuando se han vulnerado derechos fundamentales de integrantes de una misma familia".

En este punto, y ante los rápidos cuestionamientos que se puedan plantear al leer el párrafo anterior, cabe señalar que el referido enfoque y/o parámetro de estudio tendría que "considerar una consecuencia diferente y más amplia que los derechos fundamentales personalísimos".

En otras palabras, ante casos similares como el de Santa Bárbara, las sentencias que se emitan deberán tener una "sanción mayor" al tratarse de una vulneración de derechos fundamentales familiares, que superen la vulneración de un derecho fundamental individual.

En efecto, el panorama humano debiera complicarse si sumamos el hecho que se están vulnerando derechos fundamentales familiares, como el caso de Zenón Osnayo Tunque que, en Santa Bárbara, asesinaron a su esposa y sus tres hijas menores; sin duda, los derechos fundamentales del señor Osnayo vulnerados superan los derechos fundamentales vulnerados de su señora e hijos, ya que se ha quedado sin su "familia" y "sin un proyecto de vida familiar".

Para reforzar la idea anterior, partamos de la naturaleza y de la dignidad humana que se manifiestan en la persona como bienes humanos, tal como se puede apreciar de la cita siguiente:

(...) La persona es un absoluto en la medida que es fin en sí misma y nunca puede ser considerada ni tratada como un medio. En esto consiste su valor o dignidad. Por ser fin y no medio, está llamada a conseguir su plena realización como persona: a todas las personas por ser tales nos corresponde lograr la máxima realización posible. 
Tendemos a ello porque somos realidades esencialmente imperfectas e inacabadas, que adquirimos grados de perfeccionamiento y consecuente realización en tanto satisfacemos nuestras necesidades y exigencias propiamente humanas. En la medida que la satisfacción de estas necesidades perfecciona al ser humano, y que bien es aquello que perfecciona al ser, la consecución de bienes humanos permite la satisfacción de necesidades humanas y la consecución de grados de perfeccionamiento y realización humanas. Los bienes humanos es lo debido a la persona humana por ser tal, y es lo debido porque es lo que le corresponde por tener la naturaleza y dignidad humanas, por eso se formulan como bienes jurídicos vinculantes. Y es que en la medida que se habla de título y deuda, se habla de derecho: estos bienes humanos que corresponden a la persona humana (deuda) por tener naturaleza y dignidad humana (título) son derechos humanos [Cursivas añadidas]. Estos bienes humanos es lo justo con la persona humana y, por esta razón, vinculan (...) (Castillo, 2010, p.93 y 94)

De este modo:

“(...) si, por ejemplo, hay la necesidad humana de tener un espacio propio donde desplegar nuestra propia individualidad, la intimidad se convierte en un bien humano, no sólo porque satisface esa necesidad humana sino porque al satisfacerla permite lograr una mayor y más plena realización humana. Así, el bien humano intimidad se convierte en lo debido a la persona humana y, por ello, en el derecho humano a la intimidad. El contenido de este derecho humano será aquello que hace que el derecho a la intimidad sea derecho a la intimidad y no otro derecho diferente (...)" (Castillo, 2010, p. 94-95)

En tal sentido, si tenemos en consideración que existen diferentes bienes humanos que se convierten en lo debido de la persona humana y con ello, se convierten en derechos fundamentales; entonces, bien podríamos manifestar que es posible sustentar un bien humano denominado "familia" que se convierta en lo debido para la persona humana y, por lo tanto, se convierta en un derecho fundamental más.

Al respecto, The New York Times publicó, el 23 de marzo de 2016, un estudio de la Universidad de Harvard sobre los secretos para una vida feliz. De acuerdo con Robert Waldinger, profesor de psiquiatría clínica en la escuela de medicina de Harvard y director del estudio, el proyecto de investigación data desde 1938 y "una y otra vez en estos 75 años", sostuvo el Dr. Waldinger, 
"nuestro estudio ha demostrado que la gente a la que le va mejor es aquella que se apoya en las relaciones con su familia, amigos y con la comunidad"11.

Lo antes señalado, se expresa asimismo en un espacio multicultural. En efecto, "(...) ambas comunidades, Andinas y Amazónicas, tienen una organización social y política basada en la familia y el parentesco, y en la asamblea comunal (...)". (Peña, p. 198)

Como se puede apreciar, los derechos fundamentales, si bien han sido desarrollados a partir de bienes humanos necesarios para la persona, pueden expandirse a un bien humano mayor que a su vez sea un bien humano de la propia persona; como, por ejemplo, "la familia".

\section{APUNTES FINALES.}

Quizás algunos pueden plantear que los "derechos fundamentales familiares" no son necesarios ya que se pueden derivar de una interpretación extensiva del caso concreto que se presente o, de la aplicación del "test de proporcionalidad" $u$ otro similar.

Sin embargo, no podemos negar el hecho que es posible establecer el concepto de un "bien humano familia" que pueda servir como "enfoque y/o parámetro de estudio y/o defensa de mayor valor cuando se han vulnerado derechos fundamentales de integrantes de una misma familia" y no depender de interpretaciones que muchas veces no se dan en primera instancia y se tienen que esperar más de 26 años, como el caso Santa Bárbara, para que se haga justicia.

Por lo que queda claro que debemos dar un paso inicial para consagrar un derecho fundamental expandido denominado "derechos fundamentales familiares" que busquen tener "sanciones mayores" al momento de sentenciar casos similares como el de Santa Bárbara.

\section{REFERENCIAS}

Landa, Cesar (1998). Protección de los Derechos Fundamentales a través del Tribunal Constitucional y la corte Interamericana. Pensamiento Constitucional. Año V N 5 .

Recuperado de:

https:/ / well.blogs.nytimes.com/2016/03/23/the-secrets-to-a-happy-life-from-a-harvard-study / ?ref=nyt-es\&mci$\mathrm{d}=$ nyt-es\&subid=article 
Castillo Córdova, Luis (2010). El contenido Constitucional de los derechos fundamentales como objeto de protección del Amparo. Anuario Iberoamericano de Justicia Constitucional. $\mathrm{N}^{\circ}$ 14. Madrid.

Peña Jumpa, Antonio (1993). Las Comunidades campesinas y nativas en la constitución Política del Perú: Un análisis exegético del artículo $89^{\circ}$ de la constitución. Derecho a la Sociedad Asociación Civil , $N^{\circ}$ 40. Lima.

Fecha de recepción $\quad$ : 27 de agosto de 2018

Fecha de aceptación $\quad$ : 25 de octubre 2018 